\title{
CXC chemokines in angiogenesis
}

\author{
John A. Belperio, ${ }^{\dagger}$ Michael P. Keane, ${ }^{\dagger}$ Douglas A. Arenberg, ${ }^{\dagger}$ Christina L. Addison, ${ }^{\dagger}$ \\ Jan E. Ehlert, ${ }^{\dagger}$ Marie D. Burdick, ${ }^{*}$ and Robert M. Strieter ${ }^{*}$ \\ *Department of Medicine, Division of Pulmonary and Critical Care Medicine, University of California, Los Angeles \\ School of Medicine; and ${ }^{\dagger}$ Department of Internal Medicine, Division of Pulmonary and Critical Medicine, The \\ University of Michigan Medical School, Ann Arbor
}

\begin{abstract}
A variety of factors have been identified that regulate angiogenesis, including the $\mathrm{CXC}$ chemokine family. The CXC chemokines are a unique family of cytokines for their ability to behave in a disparate manner in the regulation of angiogenesis. CXC chemokines have four highly conserved cysteine amino acid residues, with the first two cysteine amino acid residues separated by one nonconserved amino acid residue (i.e., CXC). A second structural domain within this family determines their angiogenic potential. The $\mathrm{NH}_{2}$ terminus of the majority of the CXC chemokines contains three amino acid residues (Glu-Leu-Arg: the ELR motif), which precedes the first cysteine amino acid residue of the primary structure of these cytokines. Members that contain the $\operatorname{ELR}$ motif $\left(\mathrm{ELR}^{+}\right)$are potent promoters of angiogenesis. In contrast, members that are inducible by interferons and lack the ELR motif $\left(\mathrm{ELR}^{-}\right)$are potent inhibitors of angiogenesis. This difference in angiogenic activity may impact on the pathogenesis of a variety of disorders. J. Leukoc. Biol. 68: 1-8; 2000.
\end{abstract}

Key Words: cytokines $\cdot$ neovascularization $\cdot$ wound repair $\cdot$ tumorigenesis $\cdot$ tumor metastasis

\section{INTRODUCTION}

Angiogenesis is the formation of new blood vessels from preexisting microvasculature. Angiogenesis is a biological process that is critical to both physiological and pathological processes [1-11]. The regulation of angiogenesis depends on a dual, yet opposing balance of angiogenic and angiostatic factors that promote or inhibit neovascularization, respectively. For example, under homeostatic conditions the rate of normal capillary endothelial cell turnover is measured in months or years [12, 13], suggesting a balance in the biological effect of angiogenic and angiostatic factors. During wound repair the formation of granulation tissue is associated with a shift in the balance favoring the predominance of angiogenic factors that supports the development of new functioning capillaries within days [8]. In contrast, the latter phases of wound repair are associated with a marked decline of angiogenesis. This event correlates with the involution of granulation tissue that is concomitant with re-epithelialization. These events suggest that angiogenesis of wound repair is tightly controlled and temporally related to the imbalance of expression of angiogenic and angiostatic factors that ultimately regulates angiogenesis. The temporal imbalance in angiogenic and angiostatic factors in granulation tissue can either represent a marked reduction in the elaboration of angiogenic factors and/or a simultaneous increase in factors that inhibit neovascularization [14]. In contrast to the precise regulation of angiogenesis in wound repair, aberrant angiogenesis can lead to an imbalance in the relationship of angiogenic and angiostatic factors that favors persistent angiogenesis. This type of environment can contribute to the pathogenesis of tumor growth and metastases, and the promotion of chronic fibroproliferative disorders. The complement of angiogenic and angiostatic factors may vary among different physiological and pathological settings. However, the recognition of this dual mechanism of control is critical in order to gain insight into this complex process and understand aberrant angiogenesis associated with a variety of pathological conditions. The CXC chemokines are a unique family of cytokines that can regulate angiogenesis in a disparate manner and will be the subject of this review.

\section{CHEMOKINES, CXC CHEMOKINE RECEPTORS, AND ANGIOGENESIS}

CXC chemokines are characteristically heparin binding proteins. On a structural level, they have four highly conserved cysteine amino acid residues, with the first two cysteines separated by one nonconserved amino acid residue [15-27]. Although the CXC motif distinguishes this family from other chemokine families, a second structural domain dictates their angiogenic activity. The $\mathrm{NH}_{2}$ terminus of the majority of the CXC chemokines contain a three-amino-acid motif (Glu-LeuArg: the ELR motif), which precedes the first cysteine amino acid of the primary structure of these cytokines [15-27]. The family members that contain the ELR motif $\left(\mathrm{ELR}^{+}\right)$are potent promoters of angiogenesis [23] (Table 1). In contrast, members

Correspondence: Robert M. Strieter, M.D., Division of Pulmonary and Critical Care Medicine, Department of Medicine, UCLA School of Medicine, Room 37-131B, CHS, Box 951690, 10833 Le Conte Ave., Los Angeles, CA 90095-1690. E-mail: rstrieter@mednet.ucla.edu

Present address for JAB and MPK: Department of Medicine, Division of Pulmonary and Critical Care Medicine, University of California, Los Angeles, CA 90095.

Received January 1, 2000; revised January 15, 2000; accepted January 18, 2000 . 
TABLE 1. ELR $^{+}$and ELR ${ }^{-}$CXC Chemokines Are Angiogenic and Angiostatic Factors, Respectively

Angiogenic CXC chemokines containing the ELR motif $\left(\mathrm{ELR}^{+}\right)$ Interleukin-8 (IL-8)

Epithelial neutrophil activating protein-78 (ENA-78)

Growth-related gene alpha $(\mathrm{GRO}-\alpha)$

Growth-related gene beta (GRO- $\beta$ )

Growth-related gene gamma (GRO- $\gamma$ )

Granulocyte chemotactic protein-2 (GCP-2)

Platelet basic protein (PBP)

Connective tissue activating protein-III (CTAP-III)

Beta-thromboglobulin ( $\beta$-TG)

Neutrophil activating protein-2 (NAP-2)

Angiostatic CXC chemokines that lack the ELR motif (ELR $\left.{ }^{-}\right)$

Platelet factor-4 (PF4)

Interferon- $\boldsymbol{\gamma}$-inducible protein (IP-10)

Monokine induced by interferon- $\gamma$ (MIG)

that are induced by interferons and lack the ELR motif (ELR $\left.{ }^{-}\right)$ are potent inhibitors of angiogenesis [23, 28-30] (Table 1). Therefore, on a structural/functional level, members of the CXC chemokine family can either promote or inhibit angiogenesis, and the imbalance of the local expression of these chemokines may be important in the regulation of angiogenesis under both physiological and pathological conditions.

\section{Angiogenic $\left(\mathrm{ELR}^{+}\right) \mathrm{CXC}$ chemokines}

Members of the CXC chemokine family that behave as angiogenic factors include interleukin-8 (IL-8), epithelial neutrophil activating protein-78 (ENA-78), growth-related genes (GRO- $\alpha$, $-\beta$, and $-\gamma)$, granulocyte chemotactic protein-2 (GCP-2), and $\mathrm{NH}_{2}$-terminal truncated forms of platelet basic protein (PBP), which include connective tissue activating protein-III (CTAPIII), beta-thromboglobulin ( $\beta$-TG), and neutrophil activating protein-2 (NAP-2) [23, 31-33] (Table 1). ELR ${ }^{+}$CXC chemokines directly induce endothelial cell chemotactic and proliferative activity in vitro, and angiogenesis in vivo in the absence of preceding inflammation [23, 32-35]. Their angiogenic activity is distinct from their ability to induce inflammation.

Although a specific CXC chemokine receptor(s) that mediates the angiogenic activity of these cytokines remains to be determined, the candidate $\mathrm{CXC}$ chemokine receptors for this effect are CXCR1 and/or CXCR2. Only IL-8 and GCP-2 specifically bind to CXCR1, whereas all $\mathrm{ELR}^{+} \mathrm{CXC}$ chemokines bind to CXCR2 [15-27]. The ability of $\mathrm{ELR}^{+}$CXC chemokine ligands to bind to CXCR2 supports the notion that this represents the receptor for the mediation of angiogenic activity by $\mathrm{ELR}^{+} \mathrm{CXC}$ chemokines. This is further supported by the fact that CXCR2 has the greatest sequence homology with the recently described human Kaposi's sarcoma herpes virus-G protein-coupled receptor (KSHV-GPCR; ORF 74) [36-40].

The KSHV-GPCR demonstrates constitutive activation with the ability to cause oncogenic transformation of NIH 3T3 cells and to promote angiogenesis in vivo [36, 40]. Infection of primary endothelial cells with KSHV and expression of KSHVGPCR leads to enhanced proliferation and long-term survival [38]. The CXC chemokine ligands, IL-8 and GRO- $\alpha$, can act as agonists for KSHV-GPCR, and further augment the signaling of this receptor [41, 42]. It is interesting that introducing a single point mutation in wild-type CXCR2 and transfection of NIH 3T3 cells results in oncogenic transformation in a similar manner as KSHV-GPCR [36]. Moreover, wild-type CXCR2 expression in these cells results in cellular transformation related to autocrine stimulation by an $\mathrm{ELR}^{+} \mathrm{CXC}$ chemokine [36]. However, oncogenic transformation was not induced with either mutated CXCR1 or wild-type CXCR1 [36]. These data suggest that either constitutive activation or persistent autocrine stimulation of CXCR2 causes cellular transformation similar to KSHV-GPCR. Thus, the potential expression of CXCR2 on endothelial cells in the presence of persistent autocrine (endothelium), juxtacrine (endothelium), and paracrine (tumor cells or other activated stromal cells) stimulation with ELR? CXC chemokines has important implications in promoting angiogenesis. Future studies will delineate whether CXCR2 is the putative receptor for mediating $\mathrm{ELR}^{+} \mathrm{CXC}$ chemokine angiogenic activity.

\section{Angiostatic (ELR $\left.{ }^{-}\right)$CXC chemokines}

The angiostatic members of the CXC chemokine family include PF4, monokine induced by interferon- $\gamma$ (MIG), and interferon$\gamma$-inducible protein (IP-10) [43-48] (Table 1). Although stromal cell-derived factor (SDF-1) is another $\mathrm{ELR}^{-} \mathrm{CXC}$ chemokine, it remains unclear whether this $\mathrm{ELR}^{-} \mathrm{CXC}$ chemokine inhibits or promotes angiogenesis. SDF-1 has been found to induce in vitro migration of human umbilical vein endothelial cells $[49,50]$. Mice with targeted disruption of the SDF-1 gene perinatally die [51]. This appears to be multi-factorial and includes defects in B cell and myeloid progenitors, suggesting that SDF-1 is involved in lymphopoiesis and myelopoiesis. In addition, these mice demonstrate cardiac ventricular septal defects [51]. Recently, targeted disruption of the receptor for SDF-1, CXCR4, has demonstrated that this CXC chemokine receptor is essential for vascularization of the gastrointestinal tract, hematopoiesis, and cerebellar development in these mice $[52,53]$. In contrast to these findings, SDF- 1 can attenuate the angiogenic activity of $\mathrm{ELR}^{+} \mathrm{CXC}$ chemokines, bFGF, or VEGF [54]. Thus, the role of SDF-1 in modulating angiogenesis in the context of tumorigenesis or chronic fibroproliferative disorders awaits further study.

All three interferons (IFN- $\alpha,-\beta$, and $-\gamma$ ) stimulate the expression of IP-10 [15, 43-48]. MIG is induced only by IFN- $\gamma[15,43-48]$. Recently, a new $\mathrm{ELR}^{-}$member of the CXC chemokine family, IFN-inducible T cell alpha chemoattractant (I-TAC), has been cloned, and is induced primarily by IFN- $\gamma$ [55]. I-TAC, similar to IP-10 and MIG, inhibits neovascularization in the rat corneal micropocket (CMP) assay of angiogenesis in response to either $\mathrm{ELR}^{+} \mathrm{CXC}$ chemokines or VEGF (unpublished observation). These findings suggest that all interferon-inducible $\mathrm{ELR}^{-} \mathrm{CXC}$ chemokines are potent inhibitors of angiogenesis. Moreover, this interrelationship of interferon and interferon-inducible $\mathrm{ELR}^{-} \mathrm{CXC}$ chemokines and their biological function are directly relevant to the function of IL-18 and IL-12. The capability of IL-18 and IL-12 to induce IFN- $\gamma$ and subsequent interferon-inducible $\mathrm{ELR}^{-}$CXC chemokines explains their ability to inhibit angiogenesis [56]. Therefore, IL-12 and IL-18, via the induction of IFN- $\gamma$, will have a profound effect on the production of IP-10, MIG, and 
I-TAC. The subsequent expression of interferon-inducible $\mathrm{ELR}^{-} \mathrm{CXC}$ chemokines may represent the final common pathway and explain the mechanism for the attenuation of angiogenesis related to interferons. Although all three IFN-inducible $\mathrm{ELR}^{-} \mathrm{CXC}$ chemokines specifically bind to the CXC chemokine receptor, CXCR3 [55, 57], and the expression of CXCR3 mRNA has been associated with endothelial cells [58], it remains to be determined whether CXCR3 is the putative receptor for interferon-inducible $\mathrm{ELR}^{-} \mathrm{CXC}$ chemokine inhibition of angiogenesis.

Recently, eloquent studies have delineated potential mechanisms for the $\mathrm{ELR}^{-} \mathrm{CXC}$ chemokine, PF4, and its ability to inhibit angiogenesis that may be relevant to interferon-inducible ELR $^{-}$CXC chemokines. The ability of PF4 to bind to glycosaminoglycans (GAG; heparin and heparan sulfate) with high affinity appears to be important to several of its biological functions. PF4 inhibits endothelial cell migration, proliferation, and in vivo angiogenesis in response to bFGF or VEGF [59, 60]. Moreover, fluorescein isothiocyanate (FITC)-labeled PF4 injected systemically, selectively binds to the endothelium only in areas of active angiogenesis [61, 62]. This suggests that the microvasculature is the major target for the biological effects of PF4 during angiogenesis. PF4 has been shown to inhibit $\mathrm{bFGF}$ and $\mathrm{VEGF}_{165}$ binding to their respective receptors [63-65]. One mechanism for this effect is related to the generation of PF4-bFGF or PF4-VEGF ${ }_{165}$ heterodimeric complexes, which impairs bFGF or $\mathrm{VEGF}_{165}$ binding to their respective receptors [64-66]. bFGF must undergo dimerization in the presence of endogenous heparin in order to bind to its receptor $[65,66]$. PF4 complexes to bFGF and prevents bFGF dimerization followed by impaired receptor binding and internalization [65]. VEGF 165 possesses heparin binding ability similar to bFGF. PF4 impairs $\mathrm{VEGF}_{165}$ binding to its receptors on endothelium via a mechanism similar to what has been reported for its ability to inhibit bFGF [64]. Although the ability of PF4 to form heterodimers with bFGF and $\mathrm{VEGF}_{165}$ is one potential mechanism to inhibit bFGF and $\mathrm{VEGF}_{165}$ biological activity, it appears that PF4 may inhibit angiogenesis through additional mechanisms.

Although PF4 inhibits specific VEGF ${ }_{165}$ binding, it does not inhibit $\mathrm{VEGF}_{121}$ binding to $\mathrm{VEGF}$ receptors on endothelial cells. In contrast to $\mathrm{VEGF}_{165}, \mathrm{VEGF}_{121}$ is not a heparinbinding protein [64, 67, 68]. PF4 neither forms heterodimers with $\mathrm{VEGF}_{121}$ nor competitively interferes with $\mathrm{VEGF}_{121}$ binding to its receptor. However, PF4 directly inhibits $\mathrm{VEGF}_{121^{-}}$ induced endothelial cell proliferation [64]. These findings suggest that other mechanisms must be operative for PF4 inhibition of mitogen stimulation of endothelial cells, perhaps mediated through its own independent biological signal. Although a specific receptor for PF4 on endothelium has not yet been discovered, studies have suggested that PF4 inhibits endothelial cell cycle by preventing cell entry into $\mathrm{S}$ phase [60]. In a model system of endothelial cell stimulation independent of interaction with cell-surface GAGs, PF4 inhibits epidermal growth factor (EGF)-stimulated endothelial cell proliferation by causing a decrease in cyclin E-cyclin-dependent kinase 2 (cdk2) activity that results in attenuation of retinoblastoma protein (pRb) phosphorylation [69]. The mechanism is related to PF4-dependent sustained increase in the levels and binding of the cyclin-dependent kinase inhibitor (CKI), $\mathrm{p} 21^{\mathrm{Cipl} / \mathrm{WAF} 1}$, to the cyclin E-cdk2 complex. This inhibits cell cycle progression by preventing the down-regulation of $\mathrm{p} 21^{\mathrm{Cipl} / \mathrm{WAF} 1}$ leading to inhibition of both cyclin E-cdk2 activity and phosphorylation of pRb [69]. These studies suggest that PF4 can inhibit a variety of endothelial cell mitogens at multiple levels. These events may be relevant to interferoninducible $\mathrm{ELR}^{-}$CXC chemokines because IP-10 has been shown to compete with PF4 for binding, and inhibition of endothelial cell proliferation that may be related to inhibition of the cell cycle [29]. This supports the notion that interferoninducible $\mathrm{ELR}^{-} \mathrm{CXC}$ chemokines may have similar mechanisms for their inhibition of bFGF, VEGF, EGF, and $\mathrm{ELR}^{+}$ CXC chemokine-induced angiogenesis.

\section{$\mathrm{ELR}^{+} \mathrm{CXC}$ chemokines promote angiogenesis associated with tumorigenesis}

The $\mathrm{ELR}^{+} \mathrm{CXC}$ chemokines are important mediators of tumorigenesis related to their angiogenic properties. Although GRO- $\beta$ has been recently reported to inhibit angiogenesis [70], the concentration used in this study was 1000-fold higher $(1-10 \mu \mathrm{M})$ than what was found for its angiogenic activity (1-10 nM) [23, 54]. This would suggest that superphysiological concentrations of GRO- $\beta$ can desensitize the angiogenic response. Moreover, studies in melanoma tumors support that all GROs play a significant role in mediating tumorigenesis related to both their mitogenic and angiogenic activities. For example, GRO- $\alpha,-\beta$, and $-\gamma$ have all been found to be highly expressed in human melanoma [71]. To determine the biological significance of the presence of these $\mathrm{ELR}^{+} \mathrm{CXC}$ chemokines in melanoma, human GRO- $\alpha$, $-\beta$, and $-\gamma$ genes have been transfected into immortalized murine melanocytes [71, 72]. The persistent expression of GROs in these cells transforms their phenotype to one with anchorage-independent growth in vitro and the ability to form tumors in vivo in nude and SCID mice [71, 72]. The tumors are highly vascular and similar to the vascularity of B16 melanoma controls [71, 72]. When tumors are depleted of GROs there is a marked reduction of tumor-derived angiogenesis directly related to inhibition of tumor growth [71, 72]. These findings support the notion that the $\mathrm{ELR}^{+}$CXC chemokines, such as GRO- $\alpha$, $-\beta$, and $-\gamma$, have the ability to act both as autocrine growth factors for melanoma and as potent paracrine mediators of angiogenesis to promote tumorigenesis and metastases.

The progression and growth of ovarian carcinoma is also dependent on successful angiogenesis, and IL-8 has been determined to play a significant role in mediating human ovarian carcinoma-derived angiogenesis and tumorigenesis [73]. The expression of IL-8, bFGF, and VEGF was examined in five different human ovarian carcinoma cell lines [73]. All cell lines in vitro expressed similar levels of bFGF, however, these cells expressed either high or low levels of IL-8 or VEGF. When implanted into the peritoneum of nude mice, the highexpressing IL-8 tumors were associated with all animals dying in $<51$ days [73]. The expression of IL-8 was directly correlated with neovascularization and inversely correlated with survival, whereas VEGF expression was only correlated with production of ascites [73]. No correlation was found for bFGF with either tumor neovascularization or survival [73]. This 
study has been substantiated in patients with ovarian cancer, where ascites fluid demonstrates angiogenic activity directly correlated to IL-8 [74]. These findings support the notion that antigenic $\mathrm{ELR}^{+} \mathrm{CXC}$ chemokines play a greater role than bFGF and VEGF in mediating angiogenesis associated with ovarian cancer.

IL-8 is markedly elevated and contributes to overall angiogenic activity of non-small-cell lung cancer (NSCLC) [75]. Extending these studies to an in vivo model system of human tumorigenesis (i.e., human NSCLC/SCID mouse chimera) [76], tumor-derived IL-8 was found to be directly correlated with tumorigenesis [76]. Tumor-bearing animals depleted of IL-8 demonstrated a $>40 \%$ reduction in tumor growth and a reduction in spontaneous metastases [76]. The attenuation of tumor growth and metastases was directly correlated to reduced angiogenesis. These findings have been further corroborated through the use of several human NSCLC cell lines grown in nude mice. NSCLC cell lines that constitutively express IL-8 display greater tumorigenicity that is directly correlated to angiogenesis [77].

Although IL-8 was the first angiogenic CXC chemokine to be discovered in NSCLC, ENA-78 was found to be highly correlated with NSCLC-derived angiogenesis [78]. Surgical specimens of NSCLC tumors demonstrate a direct correlation of ENA-78 with tumor angiogenesis. These studies were extended to a SCID mouse model of human NSCLC tumorigenesis. ENA-78 expression was directly correlated with tumor growth. Moreover, when NSCLC tumor-bearing animals were depleted of ENA-78, both tumor growth and spontaneous metastases were markedly attenuated [78]. The reduction angiogenesis is also accompanied by an increase in tumor cell apoptosis, consistent with the previous observation that inhibition of tumor-derived angiogenesis is associated with increased tumor cell apoptosis [79, 80]. Similarly, in vivo and in vitro proliferation of NSCLC cells was unaffected by the presence of ENA78. Although a significant correlation of ENA-78 exists with tumor-derived angiogenesis, tumor growth, and metastases, ENA-78 depletion does not completely inhibit tumor growth. This reflects that the angiogenic activity of NSCLC tumors is related to many overlapping and potentially redundant factors acting in a parallel or serial manner.

Prostate cancer tumorigenesis and metastasis is dependent on angiogenesis [81, 82]. Serum levels of IL-8 have been found to be markedly elevated in patients with prostate cancer. These levels are highly correlated with the stage of the disease and have been determined to be an independent variable from the ratio of free/total prostate specific antigen (PSA) [83]. In fact, the combined use of free/total PSA and IL-8 levels were more effective in distinguishing prostate cancer from benign prostatic hypertrophy. This suggests that an $\mathrm{ELR}^{+} \mathrm{CXC}$ chemokine may be playing an important role in mediating prostate cancerderived angiogenesis in support of tumorigenesis and metastases. This observation in patients has been substantiated in human/SCID mice chimeras of human prostate cancer tumorigenesis [84]. Three human prostate cancer cell lines were examined for constitutive production of angiogenic $\mathrm{ELR}^{+} \mathrm{CXC}$ chemokines [84]. Tumorigenesis of the human prostate cancer cell line, PC-3, was shown to be attributable, in part, to the production of the angiogenic CXC chemokine, IL-8. Depletion of endogenous IL-8 inhibited PC-3 tumor growth in SCID mice, that was entirely attributable to inhibition of PC-3 tumorderived angiogenesis. In contrast, the human prostate cancer cell line, Dul45, was found to utilize a different angiogenic CXC chemokine, GRO- $\alpha$, to mediate tumor-derived angiogenesis. Depletion of endogenous GRO- $\alpha$, but not anti-IL-8, reduced tumor growth that was directly related to attenuated angiogenic activity. Thus, prostate cancer cell lines can utilize distinct CXC chemokines to mediate their tumorigenic potential. Similar findings have been shown in gastric carcinoma [85, 86]. The findings for the redundancy of $\mathrm{ELR}^{+} \mathrm{CXC}$ chemokines in human tumors provides the unique opportunity to target a putative receptor for $\mathrm{ELR}^{+} \mathrm{CXC}$ chemokine-mediated angiogenesis.

\section{$\mathrm{ELR}^{-} \mathrm{CXC}$ chemokines attenuate angiogenesis associated with tumorigenesis}

$\mathrm{ELR}^{-} \mathrm{CXC}$ chemokines have been shown to inhibit angiogenesis in several model systems. For example, Burkitt's lymphoma cell lines form tumors in nude mice [87]. Angiogenesis is essential for tumorigenesis of these lymphomas, analogous to carcinomas. The expression of IP-10 and MIG was found to be higher in tumors that demonstrated spontaneous regression, and was directly related to impaired angiogenesis [88]. To determine whether this effect was attributable to IP-10 or MIG, more virulent Burkitt's lymphoma cell lines were grown in nude mice and subjected to intra-tumor inoculation with either IP-10 or MIG. Both conditions resulted in marked reduction in tumor-associated angiogenesis [30, 89]. Although both IP-10 and MIG have been demonstrated to induce mononuclear cell recruitment via the interaction with their putative $\mathrm{CXC}$ chemokine receptor (CXCR3) [15-18, 44], the ability of both of these $\mathrm{ELR}^{-} \mathrm{CXC}$ chemokines to inhibit angiogenesis and induce lymphoma regression in nude mice support that these chemokines mediate their effects in a $\mathrm{T}$ cell-independent manner.

To examine the role of IP-10 in the regulation of angiogenesis in a carcinoma, the level of IP-10 from human surgical NSCLC tumor specimens was examined and found to be significantly higher in the tumor specimens than in normal adjacent lung tissue [90]. The increase in IP-10 from human NSCLC tissue was entirely attributable to the higher levels of IP-10 present in squamous cell carcinoma (SCCA) compared with adenocarcinoma. Moreover, depletion of IP-10 from SCCA surgical specimens resulted in augmented angiogenic activity [90]. The marked difference in the levels and bioactivity of IP-10 in SCCA and adenocarcinoma is clinically and pathophysiologically relevant, and represents a possible mechanism for the biological differences of these two cell types of NSCLC. Patient survival is lower, metastatic potential is higher, and evidence of angiogenesis is greater for adenocarcinoma, compared with SCCA of the lung [91-93]. These studies were extended to a SCID mouse system to examine the effect of IP-10 on human NSCLC cell line tumor growth in a T- and B cell-independent manner. SCID mice were inoculated with either adenocarcinoma or SCCA cell lines [90]. The production of IP-10 from adenocarcinoma and SCCA tumors was inversely correlated with tumor growth [90]. However, IP-10 levels were significantly higher in the SCCA, compared with adenocarci- 
noma tumors. The appearance of spontaneous lung metastases in SCID mice bearing adenocarcinoma tumors occurred after IP-10 levels from either the primary tumor or plasma had reached a nadir. In subsequent experiments, SCID mice bearing SCCA tumors were treated with either neutralizing antiIP-10 antibodies, whereas animals bearing adenocarcinoma tumors were treated with intra-tumor IP-10. Depletion of IP-10 in SCCA tumors resulted in a twofold increase in their size. In contrast, reconstitution of intra-tumor IP-10 in adenocarcinoma tumors reduced both their size and metastatic potential, which was unrelated to infiltrating neutrophils or mononuclear cells (i.e., macrophages or NK cells) and directly attributable to a reduction in tumor-associated angiogenesis.

\section{The role of angiogenic $\left(\mathrm{ELR}^{+}\right)$and angiostatic IFN-inducible (ELR ${ }^{-}$) CXC chemokines in the regulation of angiogenesis associated with chronic fibroproliferative disorders}

Angiogenesis is increasingly being recognized for its role in promoting the pathogenesis of chronic inflammatory/fibroproliferative disorders. For example, rheumatoid arthritis is associated with the unrestrained proliferation of fibroblasts and capillary blood vessels that leads to the formation of the pannus and destruction of joint spaces. Macrophages isolated from rheumatoid synovium produce pro-angiogenic factors [94]. Psoriasis is a well-known angiogenesis-dependent skin disorder that is characterized by marked dermal neovascularization. Keratinocytes isolated from psoriatic plaques demonstrate a greater production of angiogenic activity. It is interesting that this angiogenic phenotype is due, in part, to a combined defect in the overexpression of the angiogenic cytokine IL-8, and a deficiency in the production of the angiogenesis inhibitor, thrombospondin-1, resulting in a pro-angiogenic environment [95].

Idiopathic pulmonary fibrosis (IPF) is a chronic and often fatal pulmonary fibroproliferative disorder. The pathogenesis of IPF that ultimately leads to end-stage fibrosis demonstrates features of dysregulated/abnormal repair with exaggerated neovascularization/vascular remodeling, fibroproliferation, and deposition of extracellular matrix, leading to progressive fibrosis and loss of lung function. Although numerous eloquent studies have examined the biology of fibroblast proliferation and deposition of extracellular matrix (ECM) in interstitial lung disease, few studies have examined the role of angiogenesis/ vascular remodeling that may support fibroplasia and deposition of ECM in these disorders.

The existence of neovascularization in IPF was originally identified by Turner-Warwick, who examined the lungs of patients with widespread interstitial fibrosis and demonstrated neovascularization leading to anastomoses between the systemic and pulmonary microvasculatures and evidence of extensive vascular remodeling in areas of fibrosis [96]. These findings have been further substantiated with evidence of extensive neovascularization during the pathogenesis of pulmonary fibrosis in bleomycin-induced pulmonary fibrosis [97].

Recently, studies have corroborated the findings of TurnerWarwick, and have shown that the bronchoalveolar lavage fluid and lung tissue from patients with IPF have marked angiogenic activity that is almost entirely attributable to the imbalance in the overexpression of the angiogenic $\mathrm{ELR}^{+} \mathrm{CXC}$ chemokine, IL-8, compared with the relative down-regulation of the angiostatic IFN-inducible CXC chemokine, IP-10 [98]. To determine whether the imbalance in the expression of these CXC chemokines were relevant to the pathogenesis of pulmonary fibrosis, studies were extended to a murine model system of bleomycin-induced pulmonary fibrosis. In this model system, the expression and biological activity of murine macrophage inflammatory protein-2 (MIP-2; an angiogenic $\mathrm{ELR}^{+} \mathrm{CXC}$ chemokine homologous to human GRO- $\beta / \gamma$ ) and the angiostatic CXC chemokine, IP-10, were correlated to the magnitude of lung fibrosis during bleomycin-induced pulmonary fibrosis [99, 100]. MIP-2 and IP-10 were measured during bleomycininduced pulmonary fibrosis from bronchoalviolar lavage and whole lung tissue homogenates, and were found to be directly and inversely correlated, respectively, with total lung hydroxyproline levels, a measure of lung collagen deposition [99, 100]. Moreover, if either endogenous MIP-2 was depleted or exogenous IP-10 (intramuscular) was administered to the animals during bleomycin exposure, both treatment strategies resulted in marked attenuation of pulmonary fibrosis that was entirely attributable to a reduction in angiogenesis in the lung $[99,100]$. These findings support the notion that angiogenesis is critical to promote fibroplasia and deposition of ECM during pulmonary fibrosis, and that angiogenic and angiostatic factors, such as $\mathrm{ELR}^{+}$and interferon-inducible $\mathrm{ELR}^{-}$CXC chemokines play an important role in the pathogenesis of this process. Furthermore, with the recent demonstration of the efficacy of IFN- $\gamma$ treatment of IPF patients [101, 102], the above studies substantiate that IFN- $\gamma$ treatment of IPF may mediate its effect, in part, by shifting the imbalance of the expression of angiogenic $\mathrm{ELR}^{+}$and angiostatic interferon-inducible $\mathrm{ELR}^{-}$ CXC chemokines to favor an angiostatic environment leading to inhibition of dysregulated neovascularization/vascular remodeling, fibroproliferation, and deposition of extracellular matrix in IPF patients.

\section{CONCLUSION}

Angiogenesis is regulated by an opposing balance of angiogenic and angiostatic factors. CXC chemokines are a unique cytokine family that contains members that exhibit on a structural/functional basis either angiogenic or angiostatic biological activity. The above studies have demonstrated that, as a family, the CXC chemokines appear to be important in the regulation of angiogenesis associated with both tumorigenesis and the pathogenesis of chronic inflammatory/fibroproliferative disorders. These findings support the notion that therapy directed at either inhibition of angiogenic or augmentation of angiostatic CXC chemokines may be a novel approach in the treatment of solid tumors and chronic fibroproliferative disorders.

\section{ACKNOWLEDGMENTS}

This work was supported in part by National Institutes of Health Grants P50 HL60289 and CA87879 (R. M. S.), CA72543 (D. A. A.), and HL03906 (M. P. K.). 


\section{REFERENCES}

1. Auerbach, R. (1981) Angiogenesis-Inducing Factors: a Review. New York: Academic.

2. Auerbach, R., Kubai, L., Sidky, Y. (1976) Angiogenesis induction by tumors, embryonic tissues, and lymphocytes. Cancer Res. 36, 34353540 .

3. Folkman, J. (1995) Angiogenesis in cancer, vascular, rheumatoid and other disease. Nat. Med. 1, 27-31.

4. Folkman, J. (1993) Tumor angiogenesis. In Cancer Medicine, Vol. 1. (J. F. Holland, E. F. III, R. C. B. Jr., D. W. Kufe, D. L. Morton, and R. R. Weischelbaum, eds.), Philadelphia, PA: Lea \& Febiger, 153-170.

5. Folkman, J. (1992) The role of angiogenesis in tumor growth. Semin. Cancer Biol. 3, 65-71.

6. Folkman, J., Shing, Y. (1992) Angiogenesis. J. Biol. Chem. 267, 1093110934.

7. Folkman, J., Brem, H. (1992) Angiogenesis and inflammation. In Inflammation: Basic Principles and Clinical Correlates, 2nd ed. (J. I. Gallin, I. M. Goldstein, and R. Snyderman, eds.), New York: Raven, 821-839.

8. Leibovich, S. J., Wiseman, D. M. (1988) Macrophages, wound repair and angiogenesis. Prog. Clin. Biol. Res. 266, 131-145.

9. Polverini, P. J. (1995) The pathophysiology of angiogenesis. Crit. Rev. Oral Biol. Med. 6, 230-247.

10. Polverini, P. J. (1996) How the extracellular matrix and macrophages contribute to angiogenesis-dependent diseases. Eur. J. Cancer 32A, 2430-2437.

11. Polverini, P. J., Cotran, P. S., Gimbrone, M. A., Unanue, E. R. (1977) Activated macrophages induce vascular proliferation. Nature [London] 269, 804-806.

12. Engerman, R. L., Pfaffenenbach, D., Davis, M. D. (1967) Cell turnover of capillaries. Lab. Invest. 17, 738-743.

13. Tannock, I. F., Hayashi, H. S. (1972) The proliferation of capillary and endothelial cells. Cancer Res. 32, 77-82.

14. Bouck, N. (1992) Angiogenesis: a mechanism by which oncogenes and tumor suppressor genes regulate tumorigenesis. Cancer Treatment Res. 63, 359-371.

15. Luster, A. D. (1998) Chemokines-chemotactic cytokines that mediate inflammation. N. Engl. J. Med. 338, 436-445.

16. Rollins, B. J. (1997) Chemokines. Blood 90, 909-928.

17. Baggiolini, M. (1998) Chemokines and leukocyte traffic. Nature 392, 565-568

18. Baggiolini, M., Dewald, B., Moser, B. (1997) Human chemokines: an update. Annu. Rev. Immunol. 15, 675-705.

19. Baggiolini, M., Dewald, B., Walz, A. (1992) Interleukin-8 and related chemotactic cytokines. In Inflammation: Basic Principles and Clinical Correlates (J. I. Gallin, I. M. Goldstein, and R. Snyderman, eds.), New York: Raven.

20. Adams, D. H., Lloyd, A. R. (1997) Chemokines: leucocyte recruitment and activation cytokines. Lancet 349, 490-495.

21. Strieter, R. M., Kunkel, S. L., Shanafelt, A. B., Arenberg, D. A., Koch, A. E., Polverini, P. J. (1996) CXC chemokines in regulation of angiogenesis. In Chemokines in Disease (A. E. Koch and R. M. Strieter, eds.), Austin, TX: R. G Landes, 195-210.

22. Strieter, R. M., Polverini, P. J., Arenberg, D. A., Kunkel, S. L. (1995) The role of CXC chemokines as regulators of angiogenesis. Shock 4, 155160.

23. Strieter, R. M., Polverini, P. J., Kunkel, S. L., Arenberg, D. A., Burdick, M. D., Kasper, J., Dzuiba, J., Van Damme, J., Walz, A., Marriott, D., et al. (1995) The functional role of the ELR motif in CXC chemokinemediated angiogenesis. J. Biol. Chem. 270, 27348-27357.

24. Strieter, R. M., Kunkel, S. L. (1997) Chemokines and the lung. In Lung: Scientific Foundations, 2nd ed. (R. Crystal, J. West, E. Weibel, and P. Barnes, eds.), New York: Raven, 155-186.

25. Taub, D. D., Oppenheim, J. J. (1994) Chemokines, inflammation and the immune system. Ther. Immunol. 1, 229-246.

26. Walz, A., Kunkel, S. L., Strieter, R. M. (1996) CXC chemokines-an overview. In Chemokines in Disease (A. E. Koch and R. M. Strieter, ed.) Austin, TX: R. G. Landes, 1-26.

27. Balkwill, F. (1998) The molecular and cellular biology of the chemokines. J. Viral. Hepat. 5, 1-14.

28. Angiolillo, A. L., Sgadari, C., Taub, D. D., Liao, F., Farber, J. M Maheshwari, S., Kleinman, H. K., Reaman, G. H., Tosato, G. (1995 Human interferon-inducible protein 10 is a potent inhibitor of angiogenesis in vivo. J. Exp. Med. 182, 155-162.

29. Luster, A. D., Greenberg, S. M., Leder, P. (1995) The IP-10 chemokine binds to a specific cell surface heparan sulfate site shared with platelet factor 4 and inhibits endothelial cell proliferation. J. Exp. Med. 182 $219-231$.
30. Sgadari, C., Farber, J. M., Angiolillo, A. L., Liao, F., Teruya-Feldstein, J., Burd, P. R., Yao, L., Gupta, G., Kanegane, C., Tosato, G. (1997) Mig, the monokine induced by interferon-gamma, promotes tumor necrosis in vivo. Blood 89, 2635-2643.

31. Hu, D. E., Hori, Y., Fan, T. P. D. (1993) Interleukin-8 stimulates angiogenesis in rats. Inflammation 17, 135-143.

32. Koch, A. E., Polverini, P. J., Kunkel, S. L., Harlow, L. A., DiPietro, L. A., Elner, V. M., Elner, S. G., Strieter, R. M. (1992) Interleukin-8 as a macrophage-derived mediator of angiogenesis [see comments]. Science 258, 1798-1801.

33. Strieter, R. M., Kunkel, S. L., Elner, V. M., Martonyi, C. L., Koch, A. E. Polverini, P. J., Elner, S. G. (1992) Interleukin-8. A corneal factor that induces neovascularization. Am. J. Pathol. 141, 1279-1284.

34. Norrby, K. (1996) Interleukin-8 and de novo mammalian angiogenesis. Cell Prolif. 29, 315-323.

35. Yoshida, S., Ono, M., Shono, T., Izumi, H., Ishibashi, T., Suzuki, H., Kuwano, M. (1997) Involvement of interleukin-8, vascular endothelia growth factor, and basic fibroblast growth factor in tumor necrosis factor alpha-dependent angiogenesis. Mol. Cell Biol. 17, 4015-4023.

36. Burger, M., Burger, J. A., Hoch, R. C., Oades, Z., Takamori, H., Schraufstatter, I. U. (1999) Point mutation causing constitutive signaling of CXCR2 leads to transforming activity similar to Kaposi's sarcoma herpesvirus-G protein-coupled receptor. J. Immunol. 163, 2017-2022.

37. Sarid, R., Flore, O., Bohenzky, R. A., Chang, Y., Moore, P. S. (1998) Transcription mapping of the Kaposi's sarcoma-associated herpesvirus (human herpesvirus 8) genome in a body cavity-based lymphoma cell line (BC-1). J. Virol. 72, 1005-1012.

38. Flore, O., Rafii, S., Ely, S., O'Leary, J. J., Hyjek, E. M., Cesarman, E. (1998) Transformation of primary human endothelial cells by Kaposi's sarcoma-associated herpesvirus. Nature 394, 588-592.

39. Geras-Raaka, E., Arvanitakis, L., Bais, C., Cesarman, E., Mesri, E. A., Gershengorn, M. C. (1998) Inhibition of constitutive signaling of Kaposi's sarcoma-associated herpesvirus $\mathrm{G}$ protein-coupled receptor by protein kinases in mammalian cells in culture. J. Exp. Med. 187, 801-806.

40. Bais, C., Santomasso, B., Coso, O., Arvanitakis, L., Raaka, E. G., Gutkind, J. S., Asch, A. S., Cesarman, E., Gershengorn, M. C., Mesri, E. A., Gerhengorn, M. C. (1998) G-protein-coupled receptor of Kaposi's sarcoma-associated herpesvirus is a viral oncogene and angiogenesis activator [see comments]. Nature 391, 86-89 [published erratum appears in Nature (1998) 392, 210].

41. Rosenkilde, M. M., Kledal, T. N., Brauner-Osborne, H., Schwartz, T. W. (1999) Agonists and inverse agonists for the herpesvirus 8-encoded constitutively active seven-transmembrane oncogene product, ORF-74. J. Biol. Chem. 274, 956-961.

42. Gershengorn, M. C., Geras-Raaka, E., Varma, A., Clark-Lewis, I. (1998) Chemokines activate Kaposi's sarcoma-associated herpesvirus $\mathrm{G}$ proteincoupled receptor in mammalian cells in culture [see comments]. J. Clin. Invest. 102, 1469-1472.

43. Farber, J. M. (1993) HuMIG: a new member of the chemokine family of cytokines. Biochem. Biophys. Res. Commun. 192, 223-230.

44. Farber, J. M. (1997) Mig and IP-10: CXC chemokines that target lymphocytes. J. Leukoc. Biol. 61, 246-257.

45. Farber, J. M. (1990) A macrophage mRNA selectively induced by gamma-interferon encodes a member of the platelet factor 4 family of cytokines. Proc. Natl. Acad. Sci. USA 87, 5238-5242.

46. Farber, J. M. (1992) A collection of mRNA species that are inducible in the RAW 264.7 mouse macrophage cell line by gamma interferon and other agents. Mol. Cell Biol. 12, 1535-1545.

47. Luster, A. D., Unkeless, J. C., Ravetch, J. V. (1985) Gamma-interferon transcriptionally regulates an early-response gene containing homology to platelet proteins. Nature $315,672-676$.

48. Luster, A. D., Ravetch, J. V. (1987) Biochemical characterization of a gamma interferon-inducible cytokine (IP-10). J. Exp. Med. 166, 10841097.

49. Gupta, S. K., Lysko, P. G., Pillarisetti, K., Ohlstein, E., Stadel, J. M. (1998) Chemokine receptors in human endothelial cells. Functional expression of CXCR4 and its transcriptional regulation by inflammatory cytokines. J. Biol. Chem. 273, 4282-4287.

50. Salcedo, R., Wasserman, K., Young, H. A., Grimm, M. C., Howard, O. M., Anver, M. R., Kleinman, H. K., Murphy, W. J., Oppenheim, J. J. (1999) Vascular endothelial growth factor and basic fibroblast growth factor induce expression of CXCR4 on human endothelial cells: In vivo neovascularization induced by stromal-derived factor-1alpha. Am. J. Pathol. 154, 1125-1135.

51. Nagasawa, T., Hirota, S., Tachibana, K., Takakura, N., Nishikawa, S., Kitamura, Y., Yoshida, N., Kikutani, H., Kishimoto, T. (1996) Defects of $\mathrm{B}$-cell lymphopoiesis and bone-marrow myelopoiesis in mice lacking the CXC chemokine PBSF/SDF-1. Nature 382, 635-638. 
52. Tachibana, K., Hirota, S., Iizasa, H., Yoshida, H., Kawabata, K., Kataoka, Y., Kitamura, Y., Matsushima, K., Yoshida, N., Nishikawa, S., Kishimoto, T., Nagasawa, T. (1998) The chemokine receptor CXCR4 is essential for vascularization of the gastrointestinal tract [see comments]. Nature 393, 591-594.

53. Zou, Y. R., Kottmann, A. H., Kuroda, M., Taniuchi, I., Littman, D. R. (1998) Function of the chemokine receptor CXCR4 in haematopoiesis and in cerebellar development [see comments]. Nature 393, 595-599.

54. Arenberg, D. A., Polverini, P. J., Kunkel, S. L., Shanafelt, A., Strieter, R. M. (1997) In vitro and in vivo systems to assess role of C-X-C chemokines in regulation of angiogenesis. Meth. Enzymol. 288, 190220.

55. Cole, K. E., Strick, C. A., Paradis, T. J., Ogborne, K. T., Loetscher, M., Gladue, R. P., Lin, W., Boyd, J. G., Moser, B., Wood, D. E., Sahagan, B. G., Neote, K. (1998) Interferon-inducible T cell alpha chemoattractant (I-TAC): a novel non-ELR CXC chemokine with potent activity on activated $\mathrm{T}$ cells through selective high affinity binding to CXCR3. J. Exp. Med. 187, 2009-2021.

56. Coughlin, C. M., Salhany, K. E., Wysocka, M., Aruga, E., Kurzawa, H., Chang, A. E., Hunter, C. A., Fox, J. C., Trinchieri, G., Lee, W. M. F. (1998) Interleukin-12 and interleukin-18 synergistically induce murine tumor regression which involves inhibition of angiogenesis. J. Clin. Invest. 101, 1441-1452.

57. Loetscher, M., Gerber, B., Loetscher, P., Jones, S. A., Piali, L., ClarkLewis, I., Baggiolini, M., Moser, B. (1996) Chemokine receptor specific for IP10 and mig: structure, function, and expression in activated Tlymphocytes [see comments]. J. Exp. Med. 184, 963-969.

58. Soto, H., Wang, W., Strieter, R. M., Copeland, N. G., Gilbert, D. J., Jenkins, N. A., Hedrick, J., Zlotnik, A. (1998) The CC chemokine 6Ckine binds the CXC chemokine receptor CXCR3. Proc. Natl. Acad. Sci. USA 95, 8205-8210.

59. Maione, T. E., Gray, G. S., Petro, J., Hunt, A. J., Donner, A. L., Bauer, S. I., Carson, H. F., Sharpe, R. J. (1990) Inhibition of angiogenesis by recombinant human platelet factor-4 and related peptides. Science 247 , 77-79.

60. Gupta, S. K., Singh, J. P. (1994) Inhibition of endothelial cell proliferation by platelet factor- 4 involves a unique action on $\mathrm{S}$ phase progression. J. Cell Biol. 127, 1121-1127.

61. Hansell, P., Maione, T. E., Borgstrom, P. (1995) Selective binding of platelet factor 4 to regions of active angiogenesis in vivo. Am. J. Physiol. 269, H829-H836.

62. Borgstrom, P., Discipio, R., Maione, T. E. (1998) Recombinant platelet factor 4, an angiogenic marker for human breast carcinoma. Anticancer Res. 18, 4035-4041.

63. Sato, Y., Abe, M., Takaki, R. (1990) Platelet factor 4 blocks the binding of basic fibroblast growth factor to the receptor and inhibits the spontaneous migration of vascular endothelial cells. Biochem. Biophys. Res. Commun. 172, 595-600.

64. Gengrinovitch, S., Greenberg, S. M., Cohen, T., Gitay-Goren, H., Rockwell, P., Maione, T. E., Levi, B. Z., Neufeld, G. (1995) Platelet factor-4 inhibits the mitogenic activity of $\mathrm{VEGF}_{121}$ and $\mathrm{VEGF}_{165}$ using several concurrent mechanisms. J. Biol. Chem. 270, 15059-15065.

65. Perollet, C., Han, Z. C., Savona, C., Caen, J. P., Bikfalvi, A. (1998) Platelet factor 4 modulates fibroblast growth factor 2 (FGF-2) activity and inhibits FGF-2 dimerization. Blood 91, 3289-3299.

66. Jouan, V., Canron, X., Alemany, M., Caen, J. P., Quentin, G., Plouet, J., Bikfalvi, A. (1999) Inhibition of in vitro angiogenesis by platelet factor4-derived peptides and mechanism of action. Blood 94, 984-993.

67. Houck, K. A., Leung, D. W., Rowland, A. M., Winer, J., Ferrara, N. (1992) Dual regulation of vascular endothelial growth factor bioavailability by genetic and proteolytic mechanisms. J. Biol. Chem. 267, 2603126037.

68. Houck, K. A., Ferrara, N., Winer, J., Cachianes, G., Li, B., Leung, D. W. (1991) The vascular endothelial growth factor family: identification of a fourth molecular species and characterization of alternative splicing of RNA. Mol. Endocrinol. 5, 1806-1814.

69. Gentilini, G., Kirschbaum, N. E., Augustine, J. A., Aster, R. H., Visentin, G. P. (1999) Inhibition of human umbilical vein endothelial cell proliferation by the CXC chemokine, platelet factor 4 (PF4), is associated with impaired downregulation of p21(Cipl/WAF1). Blood 93, 25-33.

70. Cao, Y., Chen, C., Weatherbee, J. A., Tsang, M., Folkman, J. (1995) gro-beta, a -C-X-C- chemokine, is an angiogenesis inhibitor that suppresses the growth of Lewis lung carcinoma in mice. J. Exp. Med. 182, $2069-2077$.

71. Luan, J., Shattuck-Brandt, R., Haghnegahdar, H., Owen, J. D., Strieter, R., Burdick, M., Nirodi, C., Beauchamp, D., Johnson, K. N., Richmond, A. (1997) Mechanism and biological significance of constitutive expres- sion of MGSA/GRO chemokines in malignant melanoma tumor progression. J. Leukoc. Biol. 62, 588-597.

72. Owen, J. D., Strieter, R., Burdick, M., Haghnegahdar, H., Nanney, L., Shattuck-Brandt, R., Richmond, A. (1997) Enhanced tumor-forming capacity for immortalized melanocytes expressing melanoma growth stimulatory activity/growth-regulated cytokine beta and gamma proteins. Int. J. Cancer 73, 94-103.

73. Yoneda, J., Kuniyasu, H., Crispens, M. A., Price, J. E., Bucana, C. D., Fidler, I. J. (1998) Expression of angiogenesis-related genes and progression of human ovarian carcinomas in nude mice. J. Natl. Cancer Inst. $90,447-454$

74. Gawrychowski, K., Skopinska-Rozewska, E., Barcz, E., Sommer, E., Szaniawska, B., Roszkowska-Purska, K., Janik, P., Zielinski, J. (1998) Angiogenic activity and interleukin-8 content of human ovarian cancer ascites. Eur. J. Gynaecol. Oncol. 19, 262-264.

75. Smith, D. R., Polverini, P. J., Kunkel, S. L., Orringer, M. B., Whyte, R. I., Burdick, M. D., Wilke, C. A., Strieter, R. M. (1994) Inhibition of IL-8 attenuates angiogenesis in bronchogenic carcinoma. J. Exp. Med. 179, 1409-1415.

76. Arenberg, D. A., Kunkel, S. L., Polverini, P. J., Glass, M., Burdick, M. D., Strieter, R. M. (1996) Inhibition of interleukin-8 reduces tumorigenesis of human non-small cell lung cancer in SCID mice. J. Clin. Invest. 97, 2792-2802.

77. Yatsunami, J., Tsuruta, N., Ogata, K., Wakamatsu, K., Takayama, K., Kawasaki, M., Nakanishi, Y., Hara, N., Hayashi, S. (1997) Interleukin-8 participates in angiogenesis in non-small cell, but not small cell carcinoma of the lung. Cancer Lett. 120, 101-108.

78. Arenberg, D. A., Keane, M. P., DiGiovine, B., Kunkel, S. L., Morris, S. B., Xue, Y. Y., Burdick, M. D., Glass, M. C., Iannettoni, M. D., Strieter, R. M. (1998) Epithelial-neutrophil activating peptide (ENA-78) is an important angiogenic factor in non-small cell lung cancer. J. Clin. Invest. 102, 465-472.

79. O'Reilly, M. S., Boehm, T., Shing, Y., Fukai, N., Vasios, G., Lane, W. S., Flynn, E., Birkhead, J. R., Olsen, B. R., Folkman, J. (1997) Endostatin: an endogenous inhibitor of angiogenesis and tumor growth. Cell 88, $277-285$.

80. O'Reilly, M. S., Holmgren, L., Chen, C., Folkman, J. (1996) Angiostatin induces and sustains dormancy of human primary tumors in mice. Nat. Med. 2, 689-692.

81. Bostwick, D. G., Iczkowski, K. A. (1998) Microvessel density in prostate cancer: prognostic and therapeutic utility. Semin. Urol. Oncol. 16, 118 123

82. Fregene, T. A., Khanuja, P. S., Noto, A. C., Gehani, S. K., Van Egmont, E. M., Luz, D. A., Pienta, K. J. (1993) Tumor-associated angiogenesis in prostate cancer. Anticancer Res. 13, 2377-2381.

83. Veltri, R. W., Miller, M. C., Zhao, G., Ng, A., Marley, G. M., Wright, G. L., Jr., Vessella, R. L., Ralph, D. (1999) Interleukin-8 serum levels in patients with benign prostatic hyperplasia and prostate cancer. Urology $53,139-47$.

84. Moore, B. B., Arenberg, D. A., Stoy, K., Morgan, T., Addison, C. L., Morris, S. B., Glass, M., Wilke, C., Xue, Y. Y., Sitterding, S., Kunkel, S. L., Burdick, M. D., Strieter, R. M. (1999) Distinct CXC chemokines mediate tumorigenicity of prostate cancer cells. Am. J. Pathol. 154, 1503-1512.

85. Kitadai, Y., Haruma, K., Sumii, K., Yamamoto, S., Ue, T., Yokozaki, H., Yasui, W., Ohmoto, Y., Kajiyama, G., Fidler, I. J., Tahara, E. (1998) Expression of interleukin-8 correlates with vascularity in human gastric carcinomas. Am. J. Pathol. 152, 93-100.

86. Singh, R. K., Gutman, M., Radinsky, R., Bucana, C. D., Fidler, I. J. (1994) Expression of interleukin 8 correlates with the metastatic potential of human melanoma cells in nude mice. Cancer Res. 54, 3242-3247.

87. Gurtsevitch, V. E.. O'Conor, G. T., Lenoir, G. M. (1988) Burkitt's lymphoma cell lines reveal different degrees of tumorigenicity in nude mice. Int. J. Cancer 41, 87-95.

88. Sgadari, C., Angiolillo, A. L., Cherney, B. W., Pike, S. E., Farber, J. M., Koniaris, L. G., Vanguri, P., Burd, P. R., Sheikh, N., Gupta, G., TeruyaFeldstein, J., Tosato, G. (1996) Interferon-inducible protein-10 identified as a mediator of tumor necrosis in vivo. Proc. Natl. Acad. Sci. USA 93 , 13791-13796.

89. Teruya-Feldstein, J., Jaffe, E. S., Burd, P. R., Kanegane, H., Kingma, D. W., Wilson, W. H., Longo, D. L., Tosato, G. (1997) The role of Mig, the monokine induced by interferon-gamma, and IP-10, the interferongamma-inducible protein-10, in tissue necrosis and vascular damage associated with Epstein-Barr virus-positive lymphoproliferative disease. Blood 90, 4099-4105.

90. Arenberg, D. A., Kunkel, S. L., Polverini, P. J., Morris, S. B., Burdick, M. D., Glass, M. C., Taub, D. T., Iannettoni, M. D., Whyte, R. I., Strieter, R. M. (1996) Interferon-gamma-inducible protein 10 (IP-10) is an an- 
giostatic factor that inhibits human non-small cell lung cancer (NSCLC) tumorigenesis and spontaneous metastases. J. Exp. Med. 184, 981-992.

91. Minna, J. D. (1991) Neoplasms of the lung. In Principles of Internal Medicine (K. J. Isselbacher, ed.) New York: McGraw-Hill, 1102-1110.

92. Carney, D. N. (1988) Cancers of the lungs. In Pulmonary Diseases and Disorders (A. P. Fishman, ed.) New York: McGraw-Hill, 1885-2068.

93. Yuan, A., Pan-Chyr, Y., Chong-Jen, Y., Lee, Y., Yu-Tuang, Y., ChiLong, C., Lee, L., Sow-Hsong, K., Kwen-Tay, L. (1995) Tumor angiogenesis correlates with histologic type and metastasis in non-small cell lung cancer. Am. J. Respir. Crit. Care Med. 152, 2157-2162.

94. Koch, A. E., Leibovich, S. J., Polverini, P. J. (1989) Stimulation of neovascularization by human rheumatoid synovial tissue macrophages. Arthritis Rheum. 29, 471-479.

95. Nickoloff, B. J., Mitra, R. S., Varani, J., Dixit, V. M., Polverini, P. J. (1994) Aberrant production of interleukin-8 and thrombospondin-1 by psoriatic keratinocytes mediates angiogenesis. Am. J. Pathol. 144, $820-$ 828.

96. Turner-Warwick, M. (1963) Precapillary systemic-pulmonary anastomoses. Thorax 18, 225-237.

97. Peao, M. N. D., Aguas, A. P., DeSa, C. M., Grande, N. R. (1994) Neoformation of blood vessels in association with rat lung fibrosis induced by bleomycin. Anat. Rec. 238, 57-67.
98. Keane, M. P., Arenberg, D. A., Lynch, J. P., 3rd, Whyte, R. I., Iannettoni, M. D., Burdick, M. D., Wilke, C. A., Morris, S. B., Glass, M. C., DiGiovine, B., Kunkel, S. L., Strieter, R. M. (1997) The CXC chemokines, IL-8 and IP-10, regulate angiogenic activity in idiopathic pulmonary fibrosis. J. Immunol. 159, 1437-1443.

99. Keane, M. P., Belperio, J. A., Arenberg, D. A., Burdick, M. D., Xu, Z. J., Xue, Y. Y., Strieter, R. M. (1999) IFN-gamma-inducible protein-10 attenuates bleomycin-induced pulmonary fibrosis via inhibition of angiogenesis. J. Immunol. 163, 5686-5692.

100. Keane, M. P., Belperio, J. A., Moore, T. A., Moore, B. B., Arenberg, D. A., Smith, R. E., Burdick, M. D., Kunkel, S. L., Strieter, R. M. (1999) Neutralization of the CXC chemokine, macrophage inflammatory protein-2, attenuates bleomycin-induced pulmonary fibrosis. J. Immunol. $162,5511-5518$.

101. Ziesche, R., Hofbauer, E., Wittmann, K., Petkov, V., Block, L. H. (1999) A preliminary study of long-term treatment with interferon gamma-1b and low-dose prednisolone in patients with idiopathic pulmonary fibrosis [see comments]. N. Engl. J. Med. 341, 1264-1269.

102. Du Bois, R. M. (1999) Interferon gamma-1b for the treatment of idiopathic pulmonary fibrosis [editorial; comment]. N. Engl. J. Med. 341, 1302-1304. 